\title{
Is There Still a Place for the Staca Nail Plate in the Osteosynthesis of Trochanteric Fractures? Results from 52 Cases in a Regional Hospital in a Developing Country
}

\author{
M. Sawadogo ${ }^{1 *}$, H. Kafando ${ }^{2}$, A. J. I. Ouedraogo ${ }^{1}$, S. Ouedraogo ${ }^{2}$, A. S. Korsaga ${ }^{1}$, S. Tinto ${ }^{1}$, \\ C. O. Ouedraogo ${ }^{2}$, C. Darga ${ }^{1}$ \\ ${ }^{1}$ Surgery Department of the Regional Hospital, Ouahigouya, Burkina Faso \\ ${ }^{2}$ Department of Orthopedics-Traumatology, Yalgado Ouedraogo University Hospital, Ouagadougou, Burkina Faso \\ Email: *smamoudou@hotmail.com
}

How to cite this paper: Sawadogo, M., Kafando, H., Ouedraogo, A.J.I., Ouedraogo, S., Korsaga, A.S., Tinto, S., Ouedraogo, C.O. and Darga, C. (2018) Is There Still a Place for the Staca Nail Plate in the Osteosynthesis of Trochanteric Fractures? Results from 52 Cases in a Regional Hospital in a Developing Country. Open Journal of Orthopedics, 8, 132-138.

https://doi.org/10.4236/ojo.2018.84016

Received: February 23, 2018

Accepted: April 5, 2018

Published: April 8, 2018

Copyright $\odot 2018$ by authors and Scientific Research Publishing Inc. This work is licensed under the Creative Commons Attribution International License (CC BY 4.0).

http://creativecommons.org/licenses/by/4.0/

\section{(c) (i) Open Access}

\begin{abstract}
The synthesis of trochanteric fractures has evolved considerably since the use of the Staca nail-plate in 1964. This implant, despite its age, remains a solid and reliable material for the synthesis of this type of fracture. Objective: To evaluate the anatomo-clinical and functional results of Staca nail-plate osteosynthesis of trochanteric fractures at the Regional University Hospital of Ouahigouya in Burkina Faso. Methods: We performed a retrospective study of 52 trochanteric fractures treated by Staca nail-plate in the regional university hospital of Ouahigouya between June 2007 and June 2017. There were 10 women and 42 men with a mean age of 61 years (range 17 years to 89 years). Ten stable type I and II of Ender classification fractures and 42 unstable fractures were recorded, including four pseudarthrosis and six vicious calluses. The anterolateral approach was used in all cases. In the absence of an image intensifier, we performed an arthrotomy to identify the femoral neck and set up a guide pin. Results: The reduction was satisfactory with stable synthesis in 39 cases. At last follow-up, consolidation was effective in all patients, except one. Two cases of acetabular protrusion were noted, requiring early removal of equipment. Fifty-one patients were autonomous. The overall results were considered satisfactory. Conclusion: The Staca nail-plate remains a means of solid osteosynthesis. Although it is no longer relevant in industrialized countries, it provides comparable results to new implants for the osteosynthesis of trochanteric fractures. Because of its low cost, its abandonment is not justified in low-income countries.
\end{abstract}

\section{Keywords}

Fracture, Trochanter, Staca, Nail-Plate, Burkina Faso 


\section{Introduction}

The last decades have been characterized by the appearance of a wide variety of implants for the surgical treatment of trochanteric fractures. Compression screw-plate systems and gamma-type intramedullary nails are now the reference methods for the treatment of this type of fracture. However older methods continue to be available. Among them, the Staca monoblock nail plate, was developed in 1964 by DESCAMP and KERNER in France. Its major defect is its rigidity which exposes it to the risk of articular protrusion [1] [2]. Supplied with modern, more manageable implants like Dynamic Hip Screw (DHS), Traumax, Trochanteric Hip Screw (THS), gamma nail, Proximal Femoral Nail (PFN), almost no other team uses it, but it can still be useful when we do not have other implants for the synthesis of this type of fractures. The objective of this study was to know if this osteosynthesis remained a reasoned choice by evaluating the anatomical and functional results that we obtained.

\section{Patients and Methods}

We performed a retrospective study involving 52 patients treated by Staca nail-plate for trochanteric fracture from June 2007 to June 2017. There were 10 women and 42 men, average age 61 years (range 17 years and 89 years). All fractures were post-traumatic. During the study period, 148 fractures of the proximal femoral epiphysis were recorded. There were four pseudarthrosis and six vicious calluses dating back more than a year. Forty-four (44) patients discharged against medical advice and 52 treated with other types of implants were excluded from the study. All patients admitted for trochanteric fracture and surgically treated by Staca nail-plate during the study period were included.

According to the Ender [3] classification, we noted 10 stable type I and II fractures.

Osteosynthesis was performed in a delayed emergency with an average operative time of 10.2 days (range 2 to 71 days). After waiting traction and thromboembolic prevention with low molecular weight heparin, the procedure was performed under spinal anesthesia. Preoperative planning was performed, with a precise measurement of the nail length to be used. The patient was supine on an ordinary table with a block under the buttocks. Using an anterolateral Watson-Jones approach, and in the absence of an amplifier, we performed a short arthrotomy to identify the anterior side and femoral neck direction. The reduction was obtained by traction, rotation and manipulation of the focus. A guide pin was then placed in the neck, followed by auger milling. The nail was set up on the guide pin and impacted with a hammer. Radiographic control was performed immediately postoperatively to ensure proper implant size and absence of intra-articular protrusion. After removal of the drain on the third day, the patient was lifted using crutches or a walker and the exit was allowed for a return home. The average length of stay was 15.1 days (range 4 to 88 days). The control consultations were scheduled for the 21st and 45th day, then the 3rd, 6th and 9th 
months.

The quality of the reduction and the osteosynthesis, the duration of the operation, the postoperative complications, the delay of consolidation and the degree of autonomy constituted the parameters analyzed to evaluate our results.

The quality of the reduction was assessed on the immediate postoperative images, taking into account the restoration of the cervicodiaphyseal hanger, the inter-fragmentary gap and the position of the nail in the cervix and the femoral head. So we considered that the reduction was:

1) anatomical when cervicodiaphyseal angle and anteversion of the femoral neck were identical to the healthy side with an inter-fragmentary gap of less than $5 \mathrm{~mm}$;

2) satisfactory (or acceptable) if the cervicodiaphyseal angle was between 120 and $150^{\circ}$ with an inter-fragmentary gap between 5 and $10 \mathrm{~mm}$;

3) bad if there was a large varus with an angle less than $120^{\circ}$ or a protrusion of the nail.

As for the quality of the osteosynthesis, it was appreciated in relation to the strength of the assembly and the position of the nail in the femoral neck. Thus, we considered that the quality of the osteosynthesis was:

1) good: solid mounting, nail positioned in the lower half of the neck on the AP X-ray and in the middle of the bone on the profile;

2) satisfactory (or acceptable): solid mounting, nail in the middle or in the upper half of the neck;

3) bad: malposition of the material in the bone or acetabular protrusion of the nail.

The functional results, reflecting the degree of autonomy, were assessed according to the rating of Postel Merle d'Aubigné (PMA) taking into account pain, hip mobility and walking opportunities [4].

The data collected was analyzed using the software Epi Info 3.3.2 and Excel 2007.

\section{Results}

Immediate radiological results: the reduction was anatomical in nine cases (Figure 1). It was satisfactory in 33 cases, and bad in 10 cases including 8 reductions in varus with sweeping immediately and 2 intra-articular protrusions of the nail (Figure 2).

The quality of the osteosynthesis was good in 25 cases allowing partial loading using crutches or walkers. It was acceptable in 19 cases and bad in 8 cases.

Immediate suites: the average duration of the procedure was 105 minutes (range 63 minutes to 180 minutes). At the local level, no case of infection of the operative site was noted. The average duration of hospitalization was 12.3 days (range 2 to 61 days). The mean time to consolidation was 90 days for per trochanteric fractures (80 to 110 days). For trochantero-diaphyseal fractures type VII and VIII, this delay was 95 days (range 90 to 120 days). 


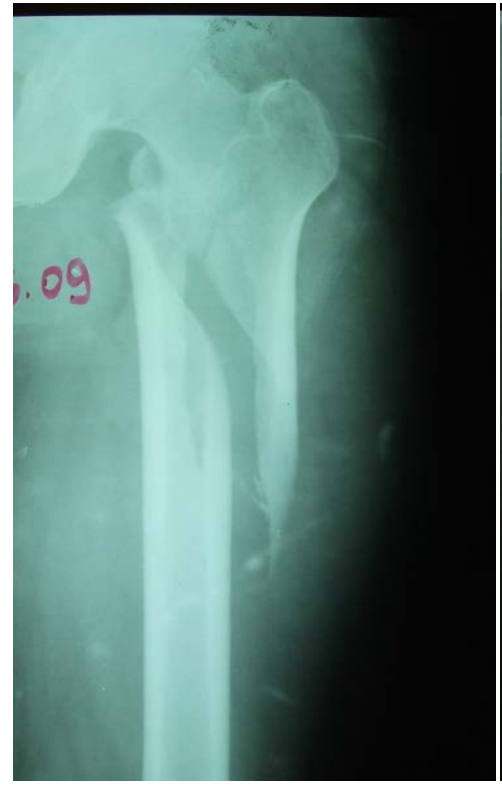

(a)

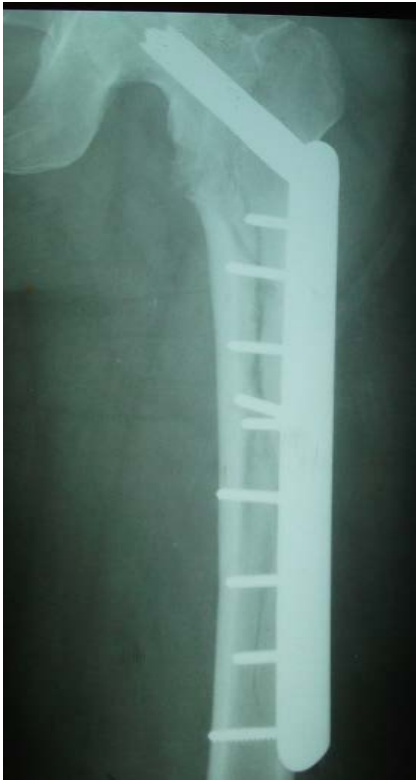

(b)

Figure 1. Trochantero-diaphyseal fracture type VII of Ender in a 49-year-old patient. (a) Preoperative; (b) Anatomical reduction.

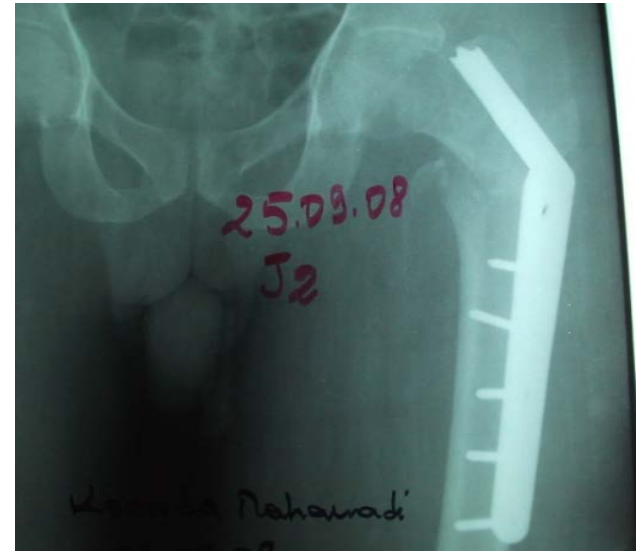

(a)



(b)

Figure 2. Poor reductions. (a) Varus reduction in a 47-year-old patient; (b) Acetabular protrusion in an 80-year-old patient with Ender's type VII fracture.

At the follow-up of 3 months, on a functional level, 46 patients had full support:

1) Forty $(76.92 \%)$ of them had a PMA score greater than 12 ;

2) Eleven (21.15\%) others had a score between 6 and 12 .

A patient who had been operated for two years was confined to bed-chair.

At the follow-up of 6 months, 40 of the 52 patients were autonomous without walking assistance. Eleven still used a walking stick. The patient with two-year-old nonunion used two crutches with a limited walking perimeter at home.

At seven and eight months, two of the eight poor coxa vara patients had a nail 
sweep that required early removal of the material with simple follow-up and good independence.

At the nine-month postoperative follow-up, all patients were autonomous with PMA scores ranging from 12 to 18 . Only the two-year-old nonunion patient was still using two crutches in and around his home (PMA score $=6$ ).

The average cost of treatment was $153 \$$ (range 125 to $352 \$$ ), representing the operative kit, the hospitalization fees and the implant cost.

\section{Discussion}

There are currently many modern implants (gamma nail, PFN, DHS, screw-plate TRAUMAX...) for the treatment of trochanteric fractures. These new techniques tend to relegate the use of older methods such as the Staca nail plate, the Ender nail, or the blade plate. However, these new techniques are not devoid of complications [2] [5] [6].

Comparing our results with those of other series using modern implants, the following observations can be made:

1) Our average duration of intervention is double the other authors. This is due to the fact that many of our patients had malunions or pseudarthrosis requiring often long osteotomy and release times. In addition, the absence of an image intensifier significantly lengthens the duration of the procedure.

2) Our reduction was anatomical or satisfactory in 42 out of 52 cases (80.76\%). The quality of osteosynthesis was satisfactory in 44 cases $(84.61 \%)$. The results reported in this regard in the literature oscillate between 80 and $90 \%$ [1] [7] [8]. On the other hand, Rapp [9] has shown that the quality of osteosynthesis depends mainly on the mechanical quality of the bone and not on the type of implant used. Our consolidation times were comparable to those of other methods (DHS, gamma nail...).

3) Functionally 22 patients in our series had partial support between the 3rd and 7th day under cover of a walker or crutches discharge. Sene and col. in Dakar [10] with the nail of Ender find the same proportions. Even with modern systems, most surgeons were initially reluctant to allow too early support [1]. Currently, with the new devices, most authors authorize depending on the quality of the osteosynthesis, an almost immediate loading [1]. The main risk of the nail-plate is acetabular protrusion because the implant is rigid and monobloc and therefore has no impaction reserve. But as Cuny [1] and Langlais [11] have shown, it is not the early loading that is responsible for this protrusion. It would only delay the occurrence. As for new implants such as DHS or gamma nail, the migration of the cervical screw or nail is rather related to the instability of the fracture, the important osteoporosis, the lack of reduction, the bad fixation of the implant and the incorrect positioning of the screw or cervical nail [2], [12], [13]. The decision of early support depends on the operator and the quality of the osteosynthesis, and not the type of implant.

4) We did not observe any cases of infection despite our precarious hygiene conditions. Cuny in Metz [1] and Le Dastumer in Paris [2] on larger series, have 
each identified only one case of sepsis. The Staca nail-plate therefore does not appear to provide more infection than these closed-focus methods [7] [8] [14].

5) Functionally, our results at the nine-month follow-up are satisfactory with a high autonomy rate of over $98 \%$. This rate is comparable to or even higher than that of modern implants [1] [7] [12] [15], although this may be partly due to the relatively young average age of patients our series. Indeed, in the western series, patients are much older with frequent cardiovascular and decubitus complications that make the final result worse [1] [7].

6) The material is simple, reliable, monobloc very solid. Its implementation is easy between trained hands. Its cost is low compared to modern implants, ( 5 to 20 or even 30 times cheaper) which in our context are not even often available.

Our study knew some limits, among others, the small size of our sample and the rarity of publications on the staca nail-plate. Only five articles were listed in PubMed between 1970 and 2001.

\section{Conclusion}

The Staca nail plate, although obsolete in the industrialized countries, retains its place in the therapeutic arsenal of fractures of the upper end of the femur, especially in areas devoid of large means. It has no particular advantage over modern implants apart from its low cost. The major risk is that of the articular protrusion of the nail. A rigorous preoperative planning and better, the use of an image intensifier, would avoid this incident. If the technique is well controlled, the results are quite comparable to other synthesis systems. Therefore, this technique should always be taught because its abandonment is not justified, especially in low income areas.

\section{References}

[1] Cuny, Ch., Scarlat, M., Moreau, P., Mainard, D. and Delagoutte, J.P. (1996) Staca nail Plate in Trochanteric Fractures. Revue de Chirurgie orthopédique, 82, 410-416.

[2] Le Dastumer, B., Le Quintrec, J.L., Forette, B. and Baulon, A. (1996) Trochanteric Fractures of the Elderly: Nail-Plate or Screw Plate? Study on 188 Geriatric Middle-Stay Patients. Annales de Réadaptation et de Médecine Physique, 39, 453-457. https://doi.org/10.1016/S0168-6054(97)80830-6

[3] Ender, J. and Simon-Weidner, R. (1970) Die Fixierung der trochantener bruche mit runden elastischen Kondylennageln. Acta Chirurgica Austriaca, 1, 40.

https://doi.org/10.1007/BF02600735

[4] Merle d'Aubigné, R. and Postel, M. (1954) Functional Results of Hip Arthroplasty with Acrylic Prosthesis. The Journal of Bone and Joint Surgery. American Volume, 36A, 451/475. https://doi.org/10.2106/00004623-195436030-00001

[5] Kempf, I., Briot, I., Briot, B., Bitar, S., Ben Abib, M. and Graf, H. (1982) The Nailing of Ender, Assessment and Technical Improvements. Sliding Lock. Revue De Chirurgie Orthopedique, 68, 199-205.

[6] Vidal, J. and Gaspa, A. (1991) The Fracture of the Upper End of the Femur. Simon, Vidal, Hérisson, Collection of Locomotor Pathology. Masson, Paris.

[7] Arnaout, A., Beya, B., Delplace, J., Vial, D. and Lecestre, P. (1993) Osteosynthesis of 
Fractures of the Trochanteric Region by Gamma Nail, about 76 Cases. Acta Orthopaedica Belgica, 59, 30-39.

[8] Traversi, R., Pfeffer, F., Galois, L., Mainard, D. and Dalagoutte, J.-P. (2002) Disassembly of Osteosynthesis Equipment for Per and Subtrochanteric Fractures in a Retrospective Study of 16 Cases. Revue de Chirurgie Orthopédique et Traumatologique, 88, 56.

[9] Rapp, E. (1993) Study of the Holding of Four Osteosynthesis Equipment in the Femoral Head. Nancy. Memory of Biomechanics and Biomaterials, 58.

[10] Sène, M., Niang, C.D., Faye, M. and Deconninck, J.C. (2003) Ender's Nail in the Treatment of Trochanteric Fractures in the Elderly. Results about a Series of 60 Cases. E-Mémoires de l'Académie Nationale de Chirurgie, 2, 6-106.

[11] Langlais, F., Burdin, P. and Burgin, T. (1987) Early Support after Osteosynthesis of the Femoral Neck by Screw-Plate (100 Cases). Revue De Chirurgie Orthopedique, 73, 624-636.

[12] Giraud, B., Dehoux, E., Jovenin, N., Madi, K., Harisboure, A., Usandizaga, G. and Segal, P. (2005) Dynamic Screw-Plate Comparison and anterograde Intra-Medullary Osteosynthesis in Perestrochanteric Fractures. Revue De Chirurgie Orthopedique et Reparatrice de l'A ppareil Moteur, 91, 732-736. https://doi.org/10.1016/S0035-1040(05)84484-8

[13] Moroni, A., Faldini, C., Pegreffi, F., Hoang-Kim, A., Vanini, F. and Giannini, S. (2005) Dynamic Hip Screw Compared with External Fixation for Treatment of Osteoporotic Pertrochanteric Fractures. A Prospective Randomized Study. The Journal of Bone and Joint Surgery. American Volume, 87, 753-759. https://doi.org/10.2106/JBJS.D.01789

[14] Germonville, T., Lecestre, P., Laimouche A. and SOR (1997) Peritrochanteric Fractures Treated by Gamma Nailing: A Study of 300 Cases. European Journal of Orthopaedic Surgery \& Traumatology, 7, 255-261. https://doi.org/10.1007/BF00595125

[15] Sawadogo, M. (2007) Osteosynthesis of Femur Proximal Epiphysis Fractures by Dunamic Hip Screw: Prospective Study of 16 Cases in the Orthopedics Department of Yalgado OUEDRAOGO University Hospital, Ouagadougou. Master of General Surgery, 49. 